\title{
Cardiovascular responses and perceived exertion of young adults to head and shoulder load carriage
}

\author{
Oyeyemi A.Y. ${ }^{1}$, Umar Z.D. ${ }^{2},{ }^{*}$ Lawan A. ${ }^{1}$, Oyeyemi A.L. ${ }^{1}$, Akanbi A.A. ${ }^{3}$, Muhammad H.S. ${ }^{3}$
}

\begin{abstract}
Objective: To determine the cardiovascular responses and perceived exertion of young adults walking and carrying a load of $10 \mathrm{~kg}$ on shoulder and the head.
\end{abstract}

Method: Healthy participants $(n=50)$ between the ages of 21 and 27 were subjected to three testing sessions at self-selected normal pace without load, and carrying a $10 \mathrm{~kg}$ load on the shoulder and on the head for 10 minutes. Cardiovascular parameters and their ratings of perceived exertion (RPE) were measured before and after testing at each session.

Results: Higher pulse pressure (correlates of stroke volume) and rate pressure product (index of myocardial oxygen uptake) values were observed following load on shoulder testing compared to no load testing values and a higher RPE value was observed for load on shoulder testing when compared to load on head testing.

Conclusion: It is conceivable that carrying load on the head can potentially be more economical than carrying load on the shoulder for this cohort of young adults.

Keywords: Cardiovascular responses, perceived exertion, load carrying, rural communities

*Corresponding author

Lawan A.

http://orcid.org/0000-0002-5942-7864

Email: aliyulawan@unimaid.edu.ng

${ }^{1}$ Department of Physiotherapy, University of Maiduguri, Maiduguri, Nigeria

${ }^{2}$ Department of Physiotherapy, Bauchi State Specialist Hospital, Bauchi, Nigeria

${ }^{3}$ Department of Physiotherapy, University of Maiduguri Teaching Hospital, Maiduguri, Nigeria 


\title{
Les réponses cardiovasculaires et l'effort perçu des jeunes adultes à la tête et l'épaule de la appui de la charge
}

\author{
Oyeyemi A.Y. ${ }^{1}$, Umar Z.D. ${ }^{2},{ }^{*}$ Lawan A. ${ }^{1}$, Oyeyemi A.L. ${ }^{1}$, Akanbi A.A. ${ }^{3}$, Muhammad H.S. ${ }^{3}$
}

\section{Résumé}

Objectif : Pour déterminer les réponses cardiovasculaires et l' effort perçu des jeunes adultes marchant et portant une charge de $10 \mathrm{~kg}$ sur l' épaule et la tête.

Méthodes: santé participants $(\mathrm{n}=50)$ pari les âges de 21 et 27 ont été soumis à trois essais sessions à un rythme normal d'auto-sélectionnée sans charge, et portant une $10 \mathrm{~kg}$ de charge sur l'épaule et sur la tête de 10 minutes. Les paramètres cardiovasculaires et leurs évaluations de l'effort perçu (EPR) ont été mesurés avant et après les tests à chaque séance.

Résultats: Des valeurs plus élevées de pression de pouls (corrélats du volume de course) et de produit de pression de débit (indice d'absorption d'oxygène du myocarde) ont été observées après un test de charge sur l'épaule par rapport aux valeurs de test sans charge et une valeur d'EPR plus élevée a été observée pour la charge sur le test d'épaule lors de la comparaison à charger sur les tests de tête.

Conclusion: Il est concevable que le transport de la charge sur la tête puisse potentiellement être plus économique que le transport de la charge sur l'épaule pour cette cohorte de jeunes adultes.

Mots-clés: Réponses cardiovasculaires, effort perçu, port de charge, communautés rurales

\author{
*Auteur Correspondant \\ Lawan A. \\ http://orcid.org/0000-0002-5942-7864 \\ Email: aliyulawan@unimaid.edu.ng
}

\footnotetext{
${ }^{1}$ Department of Physiotherapy, University of Maiduguri, Maiduguri, Nigeria

${ }^{2}$ Department of Physiotherapy, Bauchi State Specialist Hospital, Bauchi, Nigeria

${ }^{3}$ Department of Physiotherapy, University of Maiduguri Teaching Hospital, Maiduguri, Nigeria
} 


\section{INTRODUCTION}

Cardiovascular response involves a change in heart rate (HR), systolic and diastolic blood pressures (SBP and DBP) in response to exercise or stimulation from external environment. During strenuous exercise or physical activity, heart rate and cardiac output increase while vasodilatation decreases resistance in peripheral arteries to maximize the amount of oxygen delivered to the muscles (1). Exercises and physical activities also influence blood pressure, but activities which are rhythmic in nature causes less increase in blood pressure than activities that are static or involve powerful muscular movements such as weight lifting (2). Rating of Perceived Exertion (RPE) is sometimes used for determining exercise intensity levels (3) and exertion rating is a fairly good estimate of the actual heart rate during physical activity (4).

The term Activities of Daily living (ADL) function is used in health care to refer to daily self-care activities within an individual's place of residence or outdoor environment (5). Basic ADLs consist of self-care tasks including personal hygiene, dressing, self-feeding, walking and functional transfer (6). Instrumental ADLs are not necessary for fundamental functioning but can enable an individual to live independently in a community (7) and include house work, managing money, shopping, transportation within the community. Carrying load on the head and shoulder to transport essential items such as water, fire wood and food stuffs from the farm is a common instrumental ADL in the rural communities in Africa and in some other countries in Asia.

Load carriage on the body is usually done with the help of a piece of rag or leaves which is wound in a cyclic shape and placed between the load and, the head or shoulder to provide stability to the load and comfort to the person carrying the load. Possible influencing factors to load carrying ability are age, anthropometry, muscle strength, body composition and gender (8). Subjective exertion perceived during load carriage, the dimension and placement of the load have been identified as other factors (9), The body fat mass is inversely related to ability to carry load while lean mass and the ratio of lean body mass, and the ratio of lean mass to body fat mass plus external load (or load carrying index) is directly related to ability to carry load $(8,10)$. Overall it would seem that the energy cost of walking with loads depends primarily upon the walking speed, body and load weight, terrain factors and environmental heat stress.
Anecdotal reports show that African and Nepalese women are able to carry loads of up to $20 \%$ of their body mass for long distances without any strain. Anecdotal reports also show it is not uncommon to see women of the Luo and the Kikuyu tribes in Uganda, carrying loads equivalent to more than half of their body mass placed on their heads. Nevertheless, load carriage on the head or the shoulder can causes stress, discomfort and eventually head and neck injuries (11). Modern human carrying tasks have been extensively analyzed in both an ergonomic and comparative ethnographic context (12-14), but there are surprisingly few comprehensive, quantitative data on the comparative cost of simple carrying tasks (14-16).

No substantial effect on energy cost has been reported for humans carrying $7.5 \%$ of their body mass in a weighted belt (17), 20\% body mass in back packs (18) and with $10 \%$ of their body mass in weighted jackets (16). One study showed that the energy cost of walking at an optimal speed of 1.06 meter per second is only minimal and is independent of load (19), and another study show that it may not increase with load (20). Two others that focused on African women carrying a young child on their back showed minimum additional energy expenditure during house chores $(15,21)$. In the study by WallScheffler et al., (14) reduced energy cost was observed when carrying a model infant in the arms compared to the cost of carrying the model in a sling.

Technically carrying a load may cause oxygen consumption in direct proportion to the load carried although training and/or anatomical changes from childhood may improve carrying economy $(9,22,23)$. The seemingly conflicting report on the energy cost of walking per instrumental activity of daily living while bearing load on the body may therefore be due to methodological differences in the measures of energy cost, type of ADLs being performed while bearing load, parts of the body on which the loads were borne, speed of activity variation, and perhaps the conditions under which the tests were conducted. Overall, at the same intensity or speed, it could be generally more expensive in terms of energy cost to carry a load in the hands or arms or attached to the legs than to carry the same load closely attached to the trunk $(9,18)$.

In general, it appears the consensus is that the extra energy cost of walking while carrying load which is less than $20 \%$ of body weight may not be substantial $(15,16,18,21)$. However, the studies upon which this is based 
were exclusively on subjects in parts of the world other than Africa. To the best knowledge of the authors, there has been no study focusing on comparing the cardiovascular responses in carrying load on the head and shoulder from subSaharan Africa. This study aimed to determine the cardiovascular responses and rating of perceived exertion, following walking at selfselected pace on a level ground without load, compared to carrying a 10 kilograms load on the head and on the shoulder, and to explore differences in response between the walking modes.

\section{MATERIALS AND METHODS Subjects and Procedure}

A sample of 50 participants, male and female physiotherapy students were recruited using a sample of convenience. Two days before the first testing commencement of the study, eligible participants were invited to the laboratory and screened for any cardiovascular ailment and were advised on a standardized breakfast (Women $598 \mathrm{Kcal}$ while men $714 \mathrm{Kcal}$ ) not earlier than 3 hours before the next visit. Subjects were also to avoid any caffeine drink, alcohol and vigorous physical activity 24 hours before the test. Consented participants who did not follow this standardized procedure Perrusse Lechance et al, (24) were asked to return another day for the test.

On the first testing date, upon arrival at the study site, both the height and weight of the subjects were measured following standardized protocol. Participants were then asked to sit on a comfortable chair for 10 minutes before commencement of testing. Baseline HR and (Blood Pressure) BP were assessed in sitting position using a digital electronic blood pressure measuring device (Sphygmomanometer Lifesource model UB512). Thereafter, they were subjected to testing involving carrying a $10 \mathrm{Kg}$ load (sand bag) on one of either the head or the shoulder (shoulder girdle) of the non-dominant hand position for 10 minutes, while walking at their self-selected paces on a level ground. During the second testing session, not less than 24 hours after the first, subject carried the load on the alternate body position different from the first testing. All subjects then returned for the third session during which load carriage was excluded.

Participants' blood pressure, HR and perceived exertion were measured at rest and immediately after testing sessions during the three visitations. All tests were carried out between 3 and 5 pm daily in the physiotherapy gymnasium of the teaching hospital at room temperature $\left(25^{\circ} \mathrm{C}\right)$. The Body Mass Index (BMI) of the subjects were calculated as weight (kilogram) divided by the square of the height (meters). The derived indices including the mean arterial pressure (MAP), rate pressure product (RPP) and pulse pressure (PP) were calculated thus: $\mathrm{MAP}=1 / 3$ (SBP-DBP) + DBP.; RPP $=\mathrm{HR} \mathrm{x}$ $\mathrm{SBP}$, and $\mathrm{PP}=\mathrm{SBP}+\mathrm{DBP}(25,26)$. MAP is average pressure in the cardiac cycle; $\mathrm{PP}$ is a correlate of stroke volume, while RPP is an index of myocardial oxygen uptake $(27,28)$.

A written form explaining the merits/demerits as well as any foreseen benefit/harm was given to the participants and an informed consent was obtained. Ethical approval was obtained from the University of Maiduguri Teaching Hospital Research and Ethical Committee before the commencement of the study.

\section{Data analysis}

Descriptive statistics including mean and standard deviation were used to describe the physical characteristics of the participants. Analysis of Variance was used to determine the differences in baseline characteristics of cardiovascular parameters and to compare cardiovascular response and perceived exertion of participants at rest and immediately after walking without load, carrying load on the head, and carrying load on the shoulder. All data were computed for analysis using Statistical Package for Social Sciences (SPSS, RRID: SCR_002865), software version 22. Level of significance was set at an alpha of $\leq 0.05$.

\section{RESULTS \\ Physical characteristics of the participants}

A total of 50 apparently healthy clinical physiotherapy students, comprising of $30(60 \%)$ males and $20(40 \%)$ females with a mean age and body mass index of $25.5 \pm 4.4$ and $23.0 \pm 4.4 \mathrm{~kg} / \mathrm{m}^{2}$ respectively, participated in the study. Twentyseven participants had normal body mass index (54.0\%), $13(26.0 \%)$ were overweight, $6(12.0 \%)$ were under weight and $4(8.0 \%)$ were obese (Table 1).

\section{Baseline and testing cardiovascular and RPE responses}

Table 2 shows the responses of the participants before testing and after testing walking at self-selected pace without any load, load on the head and load on the shoulder. The mean HR responses at rest were $79.9 \pm 12.9$, 
$79.4 \pm 12.4$ and $79.4 \pm 12.3$ for 'no load' group, 'load on head' group and 'load on the shoulder' group respectively. HR following testing with no load, load on head and load on shoulder were $84.2 \pm 14.3,85.1 \pm 14.5$ and $86.8 \pm 13$ respectively. The mean systolic blood pressures with 'no load', 'load on head' and 'load on shoulder' groups were $122.3 \pm 13.2,122.3 \pm 13.2$ and $125.8 \pm 13.3$ respectively. RPE at baseline for 'no load' group, 'load on head' group and 'load on shoulder' group were $6.3 \pm 1.3,6.2 \pm 1.2$ and $6.2 \pm 1.2$ respectively, while the RPE for the 'no load' group, 'load on head' group and 'load on shoulder' group experimental sessions were $11.4 \pm 2.2,13.1 \pm 2.3$, $15.9 \pm 2.0$ respectively. The values for the derived indices including DBP, MAP, PP and RPP are as shown on Table 2.

\section{Comparison of baseline and testing responses}

Significantly higher HR $(\mathrm{p}<0.01)$ was observed following 'no load', 'load on head' and 'load on shoulder' groups, compared to the baseline values $(79.9 \pm 12.9,79.4 \pm 12.4$ and $79.4 \pm 12.3$ vs. $84.2 \pm 14.3,85.1 \pm 14.5$, and $86.8 \pm 13.8$ respectively). Similarly, SBP was significantly higher following no load, load on head and load on shoulder experimental groups $(117.7 \pm 15.2, \quad 117.7 \pm 11.2$ and $112.8 \pm 10.9$ respectively) compared to the baseline values. However, there were no significant differences in SBP, DBP and MAP among the three different groups. Significantly higher values $(p<0.05)$ for PP and RPP were also observed for 'load on shoulder' group value compared to 'no load' group value (48.3 \pm 11.6 vs. $42.3 \pm 9$ for PP; 1090.0 \pm 206.0 vs. $1030.0 \pm 208.0$ for RPP), but not between 'load on head' and 'no load' group values (43.9 \pm 12.7 vs. $42.3 \pm 9.7$ for PP; $105.0 \pm 273.0$ vs. $1030.0 \pm 208.0$ for RPP).

RPE for 'no load' group was significantly lower than RPE values for the two groups with load, while RPE for load on shoulder group was also significantly higher than the value for 'load on head' group $(12.5 \pm 2.2,13.1 \pm 2.3,15.9 \pm 2.0$ respectively). The results implied that walking without load can be likened to 'light' physical activity, walking with a $10 \mathrm{~kg}$ weight on head likened to 'somewhat hard' physical activity while walking with load on shoulder can be described as 'hard' physical activity. No differences in baseline or testing cardiovascular or RPE responses were observed by gender age or BMI.

\section{Comparison of load on shoulder and load on head responses}

Comparison of the parameters for 'load on head' group and 'load on shoulder' group showed that all cardiovascular parameters and derived indices were absolutely higher for 'load on shoulder' test group compared to the values for 'load on head' group. In other words, there were no significant differences between the means of HR SBP, DBP, MAP, PP and RPP values comparing 'load on head' and 'load on shoulder' test groups. However, RPE values for 'load on shoulder' test group was significantly higher $(p<0.05)$ than the values for the 'load on head' test group.

\section{DISCUSSION}

The study found the mean BMI of young adult's males and females to be $23.3 \mathrm{~kg} / \mathrm{m}^{2}$ and $23.0 \mathrm{~kg} / \mathrm{m}^{2}$ respectively. As expected, significantly higher HR, SBP, DBP, MAP, PP, RPP were observed following testing when compared to the corresponding baseline resting values. Although no study was traceable by the research team for direct comparison, higher PP and RPP values observed following load on shoulder test group compared to no load test group values are indications that carrying load on the shoulder can be argued to be unequivocally more physically demanding than walking without carrying load on head.

Based on the results in this study, it can be argued that carrying load on the shoulder can be more physically demanding than carrying load on the head or qualified as equivocal. This is so despite a significantly higher RPE values following caring load on the shoulder compared to carrying load on head as demonstrated in the study. This is because statistically, all other responses following load on the shoulder and load on the head group experimentation were comparable, although the values attributed to carrying load on the shoulder were absolutely but insignificantly higher $(p>0.05)$ than the values carrying load on the head. Potentially though carrying load on the head can be more economical than carrying load on the shoulder.

Overall, this study shows that the order of magnitude of energy expenditure during testing is increasing from no load, load on head to load on shoulder. This assertion may be supported by the perceived exertion which changed from 'no exertion at all' at baseline, to either 'light', 'somewhat hard', and 'hard or heavy' as observed for no load, load on head and load on shoulder experimental groups respectively. 
Argument for possible greater energy expenditure with load on shoulder group compared to expenditure for no load group is further supported by the significantly higher HR, PP or stroke volume and RPP or myocardial oxygen intake observed for load on shoulder group compared to no load group. However argument for greater energy expenditure with load on head compared to no load values is only tenuous, since this was only further supported by the significantly higher HR $(p<0.01)$ while carrying load on the head compared to no load experiment.

It is unclear why a small rise in HR (range 4-7) following experimentation was found despite that the perceived exertion following testing changed from 6 (no exertion at all) to 11 (light exercise or physical activity), 12 (somewhat hard exercise or physical activity) and 15 (heavy exercise or physical activity) for no load group, load on head group and load on shoulder group respectively. It is however surprising that activities that should elicit at least 50-60 jump in HR based on the relationship between HR and RPE times 10 (29) only caused a crude HR change of 5 (on average) among participants in the present study. One plausible explanation is that the subjects were apparently healthy young adults without any cardiopulmonary problems as those on medications such as beta blockers, for whom the RPE as a measure of exercise intensity was preferred. Alternatively, the subjects may have exaggerated their perceived exertion during testing.

\section{Strength and weakness of the study}

In this study testing responses were taken within 1 minute of termination of testing but not while still undergoing testing. Although not much difference in response is expected from a steady state response during testing such as at the $9^{\text {th }}$ minute, it is possible that the measurement that was taken on termination of testing as done in this study may be slightly different. Also it is unknown whether the responses will be different if the testing was done for longer minutes and therefore extrapolation of the present findings to real life situation should be done with caution. This is because load is often carried for long distances that could take more than 10 minutes and up to an hour to the target destination such as the market, farm or stream.

Absence of significant differences in the cardiovascular responses between the two load carriage testing modes should also be interpreted with caution because it is possible that the differences will be significant if more subjects were tested. It is also possible that subjects may have reduced their walking speed while carrying load compared to when no load was carried. Furthermore a $10 \mathrm{~kg}$ sandbag placed directly on body parts may cause discomfort that may be reduced if as an example foam were placed between the load and body part for cushioning discomfort. It can be argued, that the discomfort may not be totally avoided especially in subjects with ectomorphic body type. However any such possible discomfort has been forestalled because the sand contained in the bags is of fine grains and not pebbles.

This study reflects African based scientists' dilemma in dealing with the problems of lack of state-of-the art instrumentations in developing countries such as Nigeria and the poor countries in the world. On the other hand, authors' believe that the strength of this study lays in the outcome variables that were measured with instrumentations that are commonly used in clinical practice, and as such were subject to raters' errors. Therefore in spite of the above limitations, the study provides useful insights into the scale of responses to load carrying that may have direct applications to ADL and ergonomic activities of the rural African population in their communities. Given that load carrying is not specifically listed in the compendium of physical activity (30) the study is a preliminary step in quantifying the metabolic equivalent value of load carrying on the body, for possible inclusion in the compendium of physical activities.

\section{CONCLUSION}

This study suggests that walking at selfselected pace for 10 minutes without any load may be a light physical activity, while walking with the $10 \mathrm{~kg}$ load on head is somewhat a hard physical activity and walking with the load on the shoulder is a firmly a hard physical activity. Compared to the body weight, carrying even a less than substantial weight may minimally to heavily tax the body when walking and the taxing can be more when the load is carried on the shoulder than when it is carried on the head. Therefore carrying load on the head can conceivably be more economical than carrying load on the shoulder. However further study using incremental loadings to compare the physical demand of the shoulder and head load bearing modes at a preset walking speed, using robust instrumentations such as oxygen 
analyzers, is warranted.

Conflict of interest: The authors declare that there is no conflict of interest.

\section{REFERENCES}

1. Young D, Sim R. Control of Cardioac Output. Morgan \& Claypool Life Sciences; 2010.

2. Brown S, Miller W, Eason J. Exercise Physiology: Basis of Human Movement in Health and Disease. Lippincott Williams \& Wilkins, Baltimore MD; 2010.334-360 p.

3. Mellecker R. Energy expenditure and Cardiovascular responses to seated and active gaming in children. Arch Paediatr Adolesc Med. 2008;162:886-91.

4. Borg G. Psychophysical scaling with applications in physical work and perception of exertion. Scand J Work Environ Heal. 1990;16 (suppl:55-8.

5. William B. Conduction of functyion and functional deline current diogosis and Treatment Geriatrixcs. Second Edi. New York: McHrawHill; 2014. 3-4 p.

6. McDowell I, Newell C. Measuring health: A Guide to Rating Scales and Questionnaires. 2nd Editio. New York: Oxford University press.; 1996.

7. Bookman A, Harrington M, Pass L, Reisner E. Family Caregiver Handbook. Cambridge, MA: Massachusetts institute of Technology. 2007.

8. Lyons J, Allsopp A, Bilzon J. Influence of body composition upon the relative metabolic and cardiovascular demand of load carriage. Occup Med (Chic Ill). 2005;55:380-4.

9. Knapik J, Harper W, Crowell H, Leirer K, Mull B. Standard and alternative methods of stretcher carriage; performance human factors and cardiorespiratory responses. Ergonomics. 2000;43:639-52.

10. Ketko I, Hadid A, Yanovich R, Rpstein Y, Heled Y. The Load Carriage Index(LCI)-adjusting the load carried by the soldier according to body composition measurement. Extrem Physiol Med. 2015;4(Suppl 1).

11. Kanadia S. Head load reducing device. National Innovation Foundation (NIF) [Internet]. 2002. A v a i l a b l e f $\mathrm{r}$ o m : www.nif.org.in/innovation/head load reducing device_panihari/444 Accessed December 5, 2016.

12. Keren G, Epstein Y, Magazanik A, Sohar E. The cost of walking and running with and without a backpack load. Eur J Appl Physiol. 1981;46:317-24.

13. Bhambhani Y, Maikala R. Gender differences during treadmill walking with graded loads: Biochemical and physiological comparisons. , 81, . Eur J Appl Physiol. 2000;81:71-83.

14. Wall-Scheffler C, Geiger K, Steudel-Numbers K. Infant carrying: the role of increased locomotory costs in early tool development. Am J Physiol Anthropol. 2007;133:841-6.

15. Lawrence M, Sing J, Lawrence F, Whitehead R.
The energy cost of common daily activities in African women. J Clin Nutr. 1985;42:753-63.

16. Cooke C, McDonagh M, Nevill A, Davies C. Effects of load on oxygen intake in trained boys and men during treadmill running. J Appl Physiol. 1991;

17. Robertson R, Caspersen C, Allison Y, Abott R, Metz K. Differential perception of exertion and energy cost of young women while carrying load. Eur J Appl Physiol. 1982;49:69.

18. Abe D, Yanagawa K, Niihata S. Effects of load carriage, load position, and walking speed on energy cost of walking. Appl Ergon. 2004;35:329.

19. Wickler S, Hoyt D, Cogger E, Hall K. Effects of load on preferred speed and cost of transport. J Appl Physiol. 2001;90:1548-51.

20. Bastein G, Williams P, Legramandi M, Heglund N. Effects of load and speed on the energetic cost of human walking. Eur J Appl Physiol. 2005;94:76-83.

21. Watson J, Payne R, Chamberlain A, Jones R, Sellers W. The energetic cost of load-carrying and the evolution of bipedalism. J Hum Evol 54; 675683. 2008;54:675-83.

22. Maloy G, Heglund N, Prager L, Cavagna G, Taylor C. Energetic cost of carrying load: have African women discovered an economic ways? Nature. 1986;319:668.

23. Griffin T, Roberts J, Kram R. Metabolic cost of generating muscular force in human walking: insights from load carrying and speed experiment. J Appl Physiol. 2003;95:172-83.

24. Perusse L, Tremblay A, Chaput J, Poiner P, Teasdale N, Drapeau V, et al. Mental work stimulates cardiovascular responses through a reeduction in cardiac parasympathetic modulation in men and women. Bioenergetics. 2012;2(1):107.

25. McArdle W, Katch F, Katch V. Essentials of physiology. 2nd Editio. philadelphia, PA lippincott, Williams and wilkins; 2000.

26. Wilmore J, Costill D. Physiology of sport and exercise. 3rd Editio. Champaign, IL: Human kinetics; 2005.

27. Ganong W. Review of Medical Physiology. 20th Edition, editor. Lippincott, Williams and Wilkins; $2001.227 \mathrm{p}$

28. Mohrman D, Heller L. Cardiovascular Physiology. 6th Editio. New York: McGraw-Hill; 2006.

29. Center for Disease Control and Prevention. Peeceived Exertion (Borg's Rating of Perceived Exertion). National Center for for Chronic Diseases Prevention and Health Promotion., Division of Nutrition Physical Activity and Health. US Department of Hea [Internet]. 2015. A v a i l a ble f r o m : www.cdc.gov/physicalactivity/basics/measuring/ exertion.htm Accessed december \%0920, 2016.

30. Ainsworth B. Compendium of physical activities and update of activity codes and MET intensities. Med Sci Sport. 2009;44:213-27 
Table 1: Physical Characteristics of the Participants $(n=50)$

\begin{tabular}{lll}
\hline Variables & Mean $(\mathrm{SD})$ & Range \\
\hline Age (years) & $25.5 \pm 2.0$ & $24.9-26.0$ \\
Weight $(\mathrm{kg})$ & $64.9 \pm$ & $61.1-68.7$ \\
Height $(\mathrm{m})$ & $1.7 \pm 0.08$ & $1.67-1.72$ \\
BMI $\left(\mathrm{kg} / \mathrm{m}^{2}\right)$ & $23.0 \pm 4.4$ & $21.7-24.3$ \\
\hline
\end{tabular}

$\mathrm{BMI}=$ Body mass index

Table 2: Comparison of cardiovascular parameters and rated perceived exertion post testing

\begin{tabular}{|c|c|c|c|c|c|c|}
\hline \multirow[t]{2}{*}{ Variables } & \multicolumn{3}{|l|}{ Baselines } & \multicolumn{3}{|l|}{ Testing } \\
\hline & No load & Head & Shoulder & No load & Head & Shoulder \\
\hline Hear Rate & $79.9 \pm 12.9^{\mathrm{a}}$ & $79.9 \pm 12.4^{\mathrm{a}}$ & $79.4 \pm 12.3^{\mathrm{a}}$ & $84.2 \pm 14.3^{\mathrm{b}}$ & $85.1 \pm 14.5^{\mathrm{c}}$ & $86.8 \pm 13.8^{\mathrm{c}}$ \\
\hline Systolic BP & $117.7 \pm 15.2^{\mathrm{a}}$ & $117.7 \pm 11.2^{\mathrm{a}}$ & $112.8 \pm 10.9^{a}$ & $122.3 \pm 13.2^{b}$ & $122.3 \pm 13.2^{b}$ & $25.8 \pm 13.3^{b}$ \\
\hline Diastolic BP & $74.7 \pm 12.9^{\mathrm{a}}$ & $70.1 \pm 11.5^{\mathrm{a}}$ & $70.0 \pm 9.0^{\mathrm{a}}$ & $80.0 \pm 11.9^{b}$ & $77.7 \pm 10.9^{b}$ & $77.6 \pm 10.0^{\mathrm{b}}$ \\
\hline MAP & $89.0 \pm 12.4^{\mathrm{a}}$ & $83.1 \pm 16.1^{\mathrm{a}}$ & $82.9 \pm 14.9^{\mathrm{a}}$ & $94.1 \pm 11.5^{b}$ & $90.8 \pm 17.7^{b}$ & $93.7 \pm 9.8^{b}$ \\
\hline $\mathrm{PP}$ & $43.3 \pm 14.1^{\mathrm{a}}$ & $43.3 \pm 10.4^{\mathrm{a}}$ & $42.9 \pm 11.4^{\mathrm{a}}$ & $42.3 \pm 9.7$ & $43.9 \pm 12.7^{b c}$ & $48.3 \pm 11.6^{\mathrm{cd}}$ \\
\hline RPP & $939.0 \pm 197.0^{\mathrm{a}}$ & $910.0 \pm 216.0^{\mathrm{a}}$ & $893.0 \pm 198.0^{\mathrm{a}}$ & $1030.0 \pm 208.0^{\mathrm{b}}$ & $1050.0 \pm 273.0^{\mathrm{bc}}$ & \\
\hline \multicolumn{7}{|c|}{$1090.0 \pm 206.0^{\mathrm{cd}}$} \\
\hline RPE & $6.3 \pm 1.3^{\mathrm{a}}$ & $6.2 \pm 1.2^{\mathrm{a}}$ & $6.2 \pm 1.2^{\mathrm{a}}$ & $11.4 \pm 2.2^{b}$ & $13.1 \pm 2.3^{b}$ & $15.9 \pm 2.0^{\mathrm{c}}$ \\
\hline
\end{tabular}

Head denotes baseline or testing values with load on head; Shoulder denotes baseline or testing values with load on shoulder; BP denotes blood pressure; MAP denotes mean arterial pressure; PP denotes pulse pressure and RPP denotes rate pressure product; RPE denotes rated perceived exertion. For each variable Means with the same letter superscript are not significantly different from each other. Where a mean carry more than one letter superscript, the mean is not significantly different from any mean with which it shares any of the superscripts. For example for heart rate, the mean following testing with load on shoulder $(86.8 \pm 13.8)$ with superscript $\mathrm{c}$ is different from the mean with no load testing $(84.2 \pm 14.3)$ with superscript $b$, but is not different from load on shoulder testing values also with superscript $\mathrm{c}$. Also for the PP, the load on head value (48.3 \pm 11.6$)$ with superscript $\mathrm{cd}$, is different from the value when testing was done without load but is not different from load on shoulder value ( $43.9 \pm 12.7)$ with superscript bc, while the later value is not different from the value with no load testing. 